\title{
Altered growth hormone release in Huntington's chorea
}

\author{
H. J. KEOGH, R. H. JOHNSON, ${ }^{1}$ R. N. NANDA, AND W. R. SULAIMAN \\ From the University Department of Neurology, Institute of Neurological Sciences, \\ Southern General Hospital, Glasgow
}

SYNOPSIS Glucose tolerance tests have been performed on five patients with Huntington's chorea and no difference in response has been observed compared with seven controls. Insulin tolerance tests have been performed on 12 patients with Huntington's chorea and 10 controls. Blood samples were taken at regular intervals for 75 minutes and analysed for blood glucose, insulin, and growth hormone (HGH). There was no difference between the groups in the hypoglycaemia which developed. The patients, however, had an earlier elevation of HGH than the controls. The difference was highly significant $(P<0.001, P<0.02) 30$ and 35 minutes after the intravenous injection of insulin. The patients, although awake, ceased to have choreiform movements for at least the last 60 minutes of the insulin tolerance tests. Our observations of $\mathrm{HGH}$ release imply that hypothalamic activity is altered in Huntington's chorea. Further observations of HGH release may therefore be of value in its diagnosis.

The biochemistry of Huntington's chorea has been extensively studied (for reviews see Bruyn, 1968; Barbeau, 1973). The occurrence in many patients with this disorder of weight loss and excessive sweating has been attributed to altered hypothalamic function (Bruyn, 1973). Neuropathological evidence of hypothalamic involvement in Huntington's chorea has been demonstrated (Bruyn, 1968, 1973; Klintworth, 1973). In addition, altered growth hormone (HGH) release has been reported in patients with Huntington's chorea (Podolsky and Leopold, 1973). We now present further evidence of abnormalities of HGH release: we have found that patients with Huntington's chorea showed a markedly different $\mathrm{HGH}$ response to insulin induced hypoglycaemia compared with controls.

\section{METHODS}

\section{Glucose tolerance tests}

SUBJECTS Five unrelated patients (one male, four female) with Huntington's chorea were studied.

1 Address for correspondence: Dr R. H. Johnson, Institute of Neurological Sciences, Department of Neurology, Southern General Hospital, Glasgow G51 4TF.

(Accepted 21 October 1975.)
Diagnosis depended upon the presence of chorea and dementia in patients with a positive family history of the disease. Symptoms had been present for a mean of nine years (range seven-12). Their mean age was 48 years (37-57) and mean weight was $50 \mathrm{~kg}$ (36-61). Seven normal control subjects (three male, four female) were also studied. Their mean age was 50 years (30-62) and mean weight was $63 \mathrm{~kg} \mathrm{(41-74).}$

PROCEDURE All subjects fasted overnight and had received no drugs in the previous 72 hours. They were studied the following morning. A venous cannula was placed in an antecubital vein and two resting samples of blood $(10 \mathrm{ml})$ were withdrawn with approximately a 10 minute interval. Each sample was divided into a $1 \mathrm{ml}$ aliquot in a fluoride tube and a $9 \mathrm{ml}$ aliquot in a heparinized tube for later separation of plasma. Each patient was then given $50 \mathrm{~g}$ glucose orally and further blood samples were taken at $\mathbf{3 0}$ minute intervals for three hours. The blood was analysed for glucose (glucose oxidase method) and the plasma for immunoreactive insulin (Lepetit Pharmaceuticals Ltd; Albano et al., 1972). Significances of difference were examined with the Mann-Whitney non-parametric $U$ test for small samples (Mann and Whitney, 1947).

RESULTS Resting levels of glucose and insulin 244 


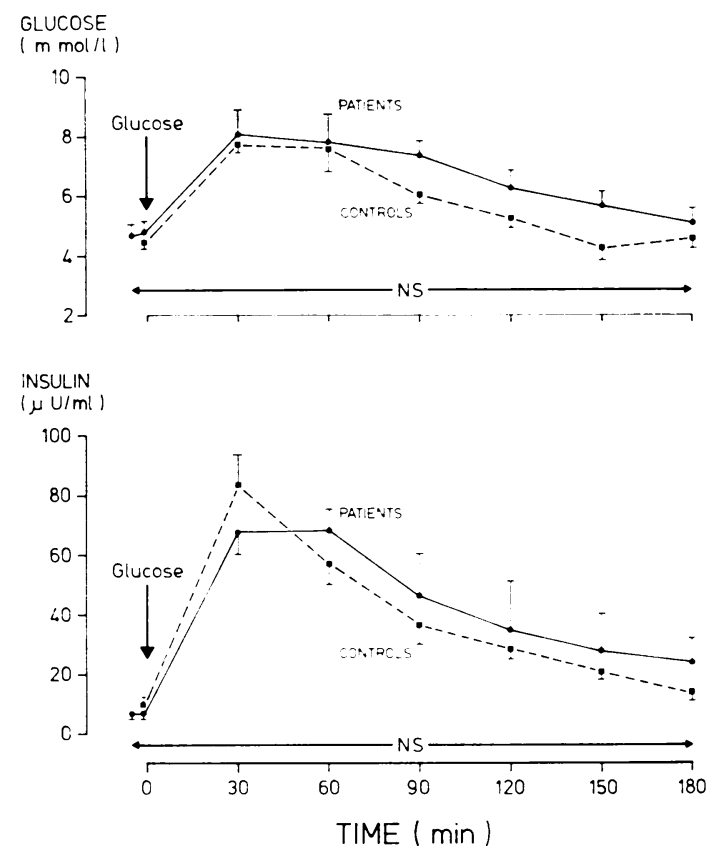

FIG. 1 Blood glucose ( $\mathrm{mmol} / \mathrm{l} \pm S E M)$ and insulin $(\mu U / m l \pm S E M)$ in five patients and seven controls during a glucose tolerance test.

were in the normal range and no significant difference between the two groups was found during the investigation (Fig. 1).

\section{Insulin tolerance tests}

SUBJECTS Twelve patients (three male, nine female) with Huntington's chorea were studied; the diagnostic criteria were as before. Symptoms had been present for a mean of 10 years (range two to 12). Their mean age was 44 years (25-63), and mean weight was $56 \mathrm{~kg}$ (35-73). Ten control subjects (five male, five female) were also studied. They had a mean age of 42 years (32-57) and mean weight of $57 \mathrm{~kg}(41-74)$. The groups were matched as closely as possible and there was no significant difference between their weights.

PROCEDURE All subjects were examined under conditions similar to the first investigation. One patient had never received phenothiazines or other drugs for chorea. All other patients had been without any drugs for at least 72 hours. Blood was taken from a venous cannula placed in an antecubital vein. Two resting samples of blood $(10 \mathrm{ml})$ were taken as before. Soluble insulin ( 0.1 units $/ \mathrm{kg}$ body wt) was then injected intravenously via the cannula and

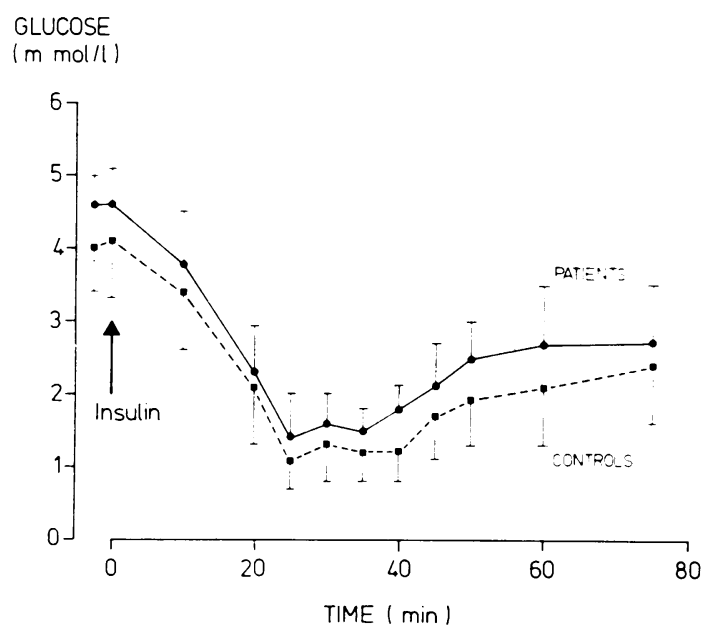

FIG. 2 Blood glucose (mmol/l $\pm S E M)$ in 12 patients and 10 controls during insulin tolerance tests $(0.1 \mathrm{U} / \mathrm{kg}$ body $w t)$.

blood samples were taken regularly for 75 minutes. In all investigations, blood samples were taken at 10 , $20,30,45,60$, and 75 minutes after insulin injection. In addition, five patients and three controls had extra samples taken at $25,35,40$, and 50 minutes. The samples were analysed for glucose and immunoreactive insulin as described above; $\mathrm{HGH}$ was analysed by a radioimmunoassay technique (Sorin Gruppo Radiochimica, Italy; Morgan, 1966). Significances of difference were examined as previously.

RESULTS Blood glucose (Fig. 2) Resting values were normal in both groups and during the investigation hypoglycaemia developed. The lowest concentrations were observed 25 minutes after injection of insulin and there was no significant difference between the groups at any time.

Plasma insulin Resting values were similar in patients and controls $(9 \mu \mathrm{U} / \mathrm{ml}$, controls; $10 \mu \mathrm{U} / \mathrm{ml}$, patients). After injection of soluble insulin, plasma insulin rose to levels of over $300 \mu \mathrm{U} / \mathrm{ml}$ in both groups at the time of the next sample, 10 minutes later.

Plasma HGH (Fig. 3) Resting levels of HGH in patients were slightly higher than in the control group but not significantly different. After injection of insulin, HGH remained constant in both 


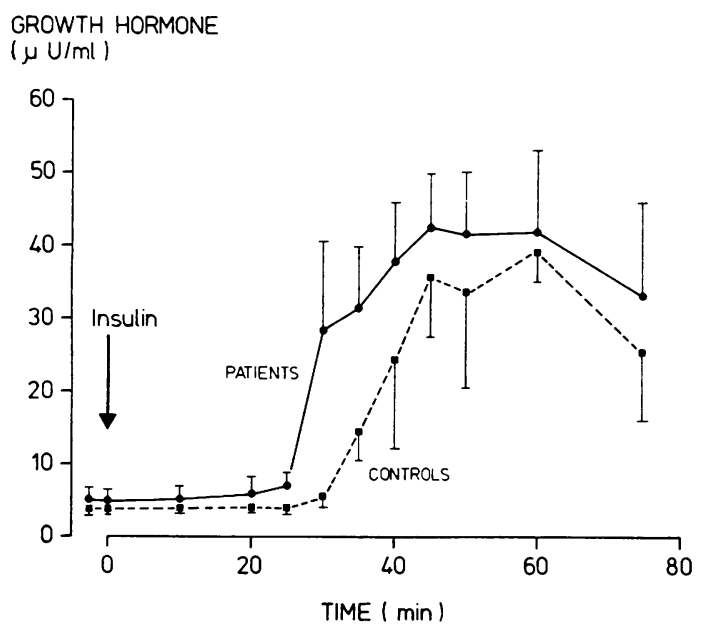

FIG. 3 Plasma human growth hormone (HGH) $(\mu U / m l \pm S E M)$ in the same subjects during the insulin tolerance test.

groups but rose dramatically after 25 minutes in the patients, whereas in the controls the elevation was slower to develop and did not begin until five to 10 minutes later. The spread of values obtained in the patients at 30 minutes was large $(18-52 \mu \mathrm{U} / \mathrm{ml})$ but it did not overlap the values for the control group (3-9 $\mu \mathrm{U} / \mathrm{ml})$. At 35 minutes the range was $20-40 \mu \mathrm{U} / \mathrm{ml}$ in the patients and $10-18 \mu \mathrm{U} / \mathrm{ml}$ in the controls and again there was no overlap. The mean concentrations of $\mathrm{HGH}$ were significantly different at 30 minutes $(\mathrm{P}<0.001)$ and at 35 minutes $(\mathrm{P}<0.02)$. The maximum levels were reached in both groups at 45 minutes and were not significantly different from each other. By the end of the investigation the concentrations had begun to fall but had not returned to resting levels.

Chorea During the investigations in the patients it was noted that their choreiform movements ceased about 30 minutes after injection of insulin. The chorea did not return until 15 to 30 minutes after the end of the investigation, making a total period of one to $1 \frac{1}{2}$ hours when the movements were absent.

\section{DISCUSSION}

The pathological changes in Huntington's chorea have been studied extensively and it is recognized that the disorder affects the basal ganglia, in particular the caudate nucleus and putamen (Bruyn, 1968; Earle, 1973; Klintworth, 1973). Other areas of the brain may be affected and it has been emphasized that the conspicuous neuronal changes which may occur in the hypothalamus might contribute to an understanding of the cachexia and disturbances of the autonomic nervous system which are frequently observed in this disorder (Bruyn, 1973). In spite of detailed pathological studies, the biochemical dysfunction in the disease is poorly understood. Barbeau (1961) suggested that there is abnormal dopamine metabolism with excessive accumulation of dopamine in the basal ganglia. Such abnormal metabolism has not been substantiated by other workers (Ehringer and Hornykiewicz, 1960; Klawans, 1971). Nevertheless, it appears that the abnormal movements characteristic of Huntington's chorea are improved by agents which interfere with dopamine metabolism in the basal ganglia. One such agent is tetrabenazine, which is a catecholamine depleter, and has been shown in a double-blind study to be of value in reducing chorea (McLellan et al., 1974). There is evidence that hypothalamic control of growth hormone releasing factor depends upon dopaminergic or adrenergic systems (Fuxe and Hökfelt, 1967, 1970; Halász, 1968; Boyd et al., 1970). Any alteration in the control of growth hormone releasing factor will influence the final release of growth hormone from the anterior pituitary and it is therefore possible to relate changes in dopaminergic or adrenergic activity in the hypothalamus to variations in the release of growth hormone. Increased motor activity would be unlikely to be an explanation of altered growth hormone values, should differences between the patients and controls be observed, as patients with Parkinsonism have normal HGH values (Kansal et al., 1972).

Glucose tolerance has previously been examined in Huntington's chorea (Podolsky et al., 1972). Six out of 10 patients reported had elevated glucose levels and hypersecretion of insulin after ingestion of glucose. In the four other patients, however, glucose and insulin responses during glucose tolerance tests were normal. The patients with abnormal glucose tolerance also had increased release of growth hormone. In our investigations of five patients 
with Huntington's chorea we observed normal resting values of glucose and insulin in agreement with previous reports (Forrest, 1957; Podolsky et al., 1972). However, the results of the glucose tolerance tests were also similar to control studies and we found no evidence of altered insulin release. We have, therefore, not substantiated the findings of Podolsky and his co-workers.

Growth hormone release has also been studied by giving L-dopa to patients with Huntington's chorea and abnormalities have been reported (Podolsky and Leopold, 1973). It has been suggested that studies of growth hormone release after giving L-dopa might act as a test for patients' relatives in whom the disease is latent and has yet to develop. It is possible, however, that L-dopa may provoke chorea in such individuals (Klawans et al., 1972). We therefore did not feel it justifiable to investigate growth hormone release in this way and have used a different stimulus, insulin induced hypoglycaemia, which is known to cause rapid release of growth hormone (Roth et al., 1963).

During the insulin test the fall in blood glucose was similar in both groups and the lowest concentrations were observed at the same time after injection of insulin. The resting levels of $\mathrm{HGH}$ of both groups were within the normal range expected, but there was a marked difference in the timing of the growth hormone increase during the investigations (Fig. 3) as the patients had an earlier rise. The mean values of the $\mathrm{HGH}$ in the patients were significantly higher at the 30 and 35 minute points $(\mathrm{P}<0.001$; $P<0.02)$. These observations suggest an alteration in the threshold for $\mathrm{HGH}$ release by the hypothalamus, perhaps due to altered dopaminergic sensitivity. It is not, however, possible to relate this to the reported pathological changes. The hypothalamic gliosis previously shown in patients with Huntington's chorea (Bruyn, 1968) could result in a reduction in $\mathrm{HGH}$ release due to a failure of normal production of growth hormone releasing factor, but we have no definite evidence of this. An alternative explanation of these findings is that the altered threshold level is a result of hypersensitivity to drugs such as phenothiazines (Klawans, 1970). However, one patient had never received them and all others had been without drugs for at least 72 hours, but their $\mathrm{HGH}$ responses were all similar.

About 25 minutes after the injection of insulin, all patients had cessation of choreiform movements for approximately the next hour. Cessation of movements could be related to depression of consciousness caused by hypoglycaemia, but we feel that this is unlikely to be the explanation as all patients were awake throughout the investigations and we checked repeatedly to see that they were capable of verbal communication. This suggests that hypoglycaemia has affected not only the pathways controlling growth hormone release, but also those affected in chorea.

Our observations have shown that there is an alteration in the pattern of growth hormone release in patients with Huntington's chorea using a standard test of injection of insulin. Our results would be in keeping with the suggestion that there is abnormal hypothalamic activity in Huntington's chorea and the emaciation frequently observed in patients with this disorder (Bruyn, 1973) may be related to this dysfunction.

We wish to thank the patients for their cooperation and Professor J. A. Simpson for encouragement. We also wish to thank Dr Jean Bolt some of whose patients were included in our study. The National Fund for Research into Crippling Diseases and the Scottish Hospital Endowments Research Trust (grant 366) kindly provided financial support.

\section{REFERENCES}

Albano, J. D. M., Ekins, R. P., Maritz, G., and Turner, R. C. (1972). A sensitive precise radioimmunoassay of serum insulin relying on charcoal preparation of bound and free hormone moieties. Acta Endocrinologica, 70, 487-509.

Barbeau, A. (1961). Dopamine and basal ganglia disease. Archives of Neurology (Chic.), 4, 97-102.

Barbeau, A. (1973). Biochemistry of Huntington's chorea. In Advances in Neurology, vol. 1, pp. 473-516. Edited by A. Barbeau, T. N. Chase, and G. W. Paulson. Raven Press: New York.

Boyd, A. E., III, Lebovitz, H. A., and Pfeiffer, J. B. (1970). Stimulation of human growth hormone secretion by L-dopa. New England Journal of Medicine, 283, 1425-1429.

Bruyn, G. W. (1968). Huntington's chorea-history, clinical and laboratory synopsis. In Handbook of Clinical Neurol$o g y$, vol. 6, pp. 298-387. Edited by P. J. Vinken and G. W. Bruyn. North Holland: Amsterdam.

Bruyn, G. W. (1973). Neuropathological changes in Huntington's chorea. In Advances in Neurology, vol. 1, pp. 399-403. Edited by A. Barbeau, T. N. Chase, and G. W. Paulson. Raven Press: New York.

Earle, K. M. (1973). Pathology and experimental models of Huntington's chorea. In Advances in Neurology, vol. 1, pp. 
340-351. Edited by A. Barbeau T. N. Chase, and G. W. Paulson. Raven Press: New York.

Ehringer, H., and Hornykiewicz, O. (1960). Verteiling von Noradrenalin und Dopamin (3-hydroxytyramin) in Gehirn des Menschen und ihr Verhalten bei Erkrankungen des extrapyramidalen systems. Klinische Wochenschrift, 38, 1236-1237.

Forrest, A. D. (1957). Some observations on Huntington's chorea. Journal of Mental Science, 103, 507-513.

Fuxe, K., and Hökfelt, T. (1967). The influence of central catecholamine neurons on the hormone secretion from the anterior and posterior pituitary. In Neurosecretion, pp. 165-177. Edited by F. Stutinsky. Springer: Berlin.

Fuxe, K., and Hökfelt, T. (1970). Participation of central monoamine neurons in the regulation of anterior pituitary function with special regard to the neuro-endocrine role of tubero-infundibular dopamine neurons. In Aspects of Neuroendocrinology, pp. 192-205. Edited by W. Bargmann and B. Scharrer. Springer: Berlin.

Halász, B. (1968). The role of the hypothalamic hypophysiotrophic area in the control of growth hormone secretion. In Growth Hormone, pp. 204-210. Edited by A. Pecite and E. E. Muller. Excerpta Medica: Amsterdam.

Kansal, P. C., Buse, J., Talbert, O. R., and Buse, M. G. (1972). The effect of L-dopa on plasma growth hormone, insulin and thyroxine. Journal of Clinical Endocrinology and Metabolism, 24, 99-105.

Klawans, H. L. (1970). A pharmacologic analysis of Huntington's chorea. European Neurology, 4, 148-163.

Klawans, H. L. (1971). Cerebrospinal fluid homovanillic acid in Huntington's chorea. Journal of the Neurological Sciences, 13, 277-279.
Klawans, H. L., Paulson, G. W., Ringel, S. P., and Barbeau, A. (1972). Use of L-dopa in the detection of presymptomatic Huntington's chorea. New England Journal of Medicine, 286, 1332-1334.

Klintworth, G. K. (1973). Huntington's chorea-morphologic contributions of a century. In Advances in Neurology, vol. 1, pp. 353-368. Edited by A. Barbeau. T. N. Chase, and G. W. Paulson. Raven Press: New York.

McLellan, D. L., Chalmers, R. J., and Johnson, R. H. (1974). A double-blind trial of tetrabenazine, thiopropazate and placebo in patients with chorea. Lancet, 1, 104-107.

Mann, H. B., and Whitney, D. R. (1947). On a test of whether one or two random variables is stochastically larger than the other. Annals of Mathematical Statistics, $18,52-54$.

Morgan, C. R. (1966). Human growth hormone immunoassay: two antibody method using ${ }^{125}$ I tracer. Proceedings of the Society for Experimental Biology and Medicine 121, 62-81.

Podolsky, S., and Leopold N. A. (1973). Biogenic amines in the hypothalamus: effect of L-dopa on human growth hormone levels in patients with Huntington's chorea. In Progress in Brain Research vol. 39, pp. 225-234. Edited by E. Zimmermann. Elsevier: New York.

Podolsky S., Leopold, N. A., and Sax, D. S. (1972). Increased frequency of diabetes mellitus in patients with Huntington's chorea. Lancet, 1, 1356-1359.

Roth, J., Glick, S. M., Yalow, R. S., and Berson, S. A. (1963) Hypoglycemia: a potent stimulus to secretion of growth hormone. Science, 140 987-988. 